\title{
Pemberdayaan Anak Putus Sekolah Melalui Kakao Sambung Pucuk
}

\section{Empowering Broken Schools Through Cocoa Connect Pucuk}

Arwanda, Program Studi Pendidikan Teknologi Pertanian Fakultas Teknik, Universitas Negeri

Makassar. Email: arwandaptp@gmail.com

Emi Mastura, Program Studi Pendidikan Teknologi Pertanian Fakultas Teknik, Universitas

Negeri Makassar. Email:

Ulfa Aulia Syamsuri, Program Studi Pendidikan Teknologi Pertanian Fakultas Teknik, Universitas Negeri Makassar. Email:

\begin{abstract}
Abstrak
Adapun yang menjadi latar belakang dilaksanakan kegiatan ini yaitu adanya masalah dalam budidaya kakao yaitu serangan Organisme Pengganggu Tanaman (OPT) seperti hama Penggerek Buah Kakao (PBK) dan penyakit Vascular Streak Dieback (VSD) serta penyakit busuk buah. Sementara itu, di Desa Patampanua sekitar 70\% anak mengalami putus sekolah dan menjadi pengangguran. Pemberdayaan anak putus sekolah melalui penyuluhan dan pelatihan merupakan alternatif yang dapat dilakukan untuk mengatasi masalah budidaya kakao dan pengangguran di Desa Patampanua. Kegiatan ini bertujuan untuk memberdayakan anak putus sekolah di Desa Patampanua, Kecamatan Marioriwawo, Kabupaten Soppeng, dalam melaksanakan pembibitan kakao metode sambung pucuk (okulasi) persilangan dengan kakao unggul. Hasil yang dicapai setelah pelaksanaan dinilai dari aspek pengetahuan dan keterampilan melalui pre tes dan post tes. Pada aspek pengentahuan nilai rata-rata peserta pada pre tes yaitu 1.5 dan pada post tes yaitu 8.65. Pada aspek keterampilan pada pelatihan pertama dari 100 bibit yang disambung pucuk hanya 30 yang berhasil tumbuh, akan tetapi pada saat pelatiahan yang kedua yaitu dari 100 bibit yang disambung 70 bibit berhasil tumbuh. Potensi sambung pucuk kakao kedepannya dapat dikembangkan melalui penyediaan jasa pembibitan kakao dan pengembangan usaha pembibitan kakao. Dengan adanya kegiatan ini mampu mengatasi masalah dalam budidaya kakao melalui sambung pucuk serta mengurangi pengangguran pada anak putus sekolah di Desa Patampanua, Kecamatan Marioriwawo, Kabupaten Soppeng.
\end{abstract}

Kata Kunci : Kakao, Okulasi, Anak Putus Sekolah.

\begin{abstract}
The background of this activity is the existence of problems in cocoa cultivation, namely the attack of Plant Disturbing Organisms (OPT) such as Cocoa Fruit Borer (PBK) and Vascular Streak Dieback (VSD) and fruit rot disease. Meanwhile in Patampanua Village about $70 \%$ of children experience dropping out of school and become unemployed. Empowerment of out of school children through counseling and training is an alternative that can be done to overcome the problem of cocoa cultivation and unemployment in Patampanua Village. This activity aims to empower out-of-school children in Patampanua Village, Marioriwawo District, Soppeng Regency, in carrying out cocoa nurseries of grafting methods with superior
\end{abstract}


cocoa. The results achieved after the implementation were assessed from aspects of knowledge and skills through pre-test and post-test. In the knowledge aspect, the average score of the participants in the pre test was 1.5 and in the post test was 8.65. On the skill aspect In the first training of 100 seedlings that were budded, only 30 were able to grow, but at the time of the second training, of the 100 seedlings which were joined by 70, the seedlings were successfully growing. Future cocoa shoot potential can be developed through the provision of cocoa nursery services and cocoa nursery business development. With this activity, it is able to overcome problems in cocoa cultivation through top grafting and reduce unemployment in school dropouts in Patampanua Village, Marioriwawo District, Soppeng Regency.

Keywords: Cocoa, Grafting, Dropout Children.

\section{Latar Belakang}

Secara geografis wilayah Kabupaten Soppeng berbatasan: Sebelah Utara berbatasan dengan Kabupaten Sidenreng Rappang dan Kabupaten Wajo, sebelah Timur berbatasan dengan Kabupaten Wajo dan Kabupaten Bone, sebelah Selatan berbatasan dengan Kabupaten Bone dan sebelah Barat berbatasan dengan Kabupaten Barru. Jarak Kabupaten Soppeng dari ibukota Propinsi Sulawesi Selatan yakni $172 \mathrm{~km}$. Luas wilayah kabupaten ini adalah 1500 km2 dengan ibukota Kabupaten adalah Watansoppeng, Wilayah Kabupaten Soppeng terbagi atas 8 (delapan) kecamatan.

Di desa Patampanua jumlah penduduk yaitu 2.006 orang dari 561 jumlah rumah tangga dan jumlah penduduk laki-laki 970 orang dan jumlah penduduk perempuan 1.036 orang (BPS Kabupaten Soppeng,2017). Di desa Patampanua sekitar 70\% anak yang mengalami putus sekolah dan sebagaian besar anak yang telah menyelesaikan pendidikan di tinggkat sekolah menengah tidak melanjutkan kejenjang yang lebih tinggi karena faktor ekonomi dan faktor keluarga. Hal tersebut menjadi kurang baik apabilah anak yang putus sekolah dan yang tidak melanjutkan pedidikan hanya menjadi pengangguran di Desa Patampanua. Anak mudah yang tidak mempunai kesibukan atau pekerjaan cenderung melakukan hal-hal yang negatif yang dapat menganggu kemanan dan ketentraman masyarakat seperti mencuri,mabuk-mabukan narkoba dan perkelahian.

Sementara itu di Desa Patampanua Kecamatan Marioriawa Kabupaten Soppeng mengalami masalah dalam budidaya kakao yaitu serangan Organisme Pengganggu Tanaman (OPT) seperti hama Penggerek Buah Kakao (PBK) dan penyakit Vascular Streak Dieback (VSD) serta penyakit busuk buah, penurunan tingkat produktifitas. Kurangnya pengetahuan masyarakat tentang bagaimana cara untuk mengatasi masalah tersebut sehingga banyak petani kakao yang beralih bercocok tanam, padahal kakao memiliki potensi untuk meningkatakan kesejahteraan masyarakat karena nilai jualnya yang tinggi dan produktifitasnya yang cukup tinggi. Bahkan beberapa petani membiarkan kebun kakaonya begitu saja karena dianggap sudah tidak dapat menunjang kehidupan ekonomi dalam keluarga. 
Penggunaan bibit unggul menjadi salah satu alternatif yang efektif dalam mengatasi masalah kakao. Hal ini karena, bibit unggul memiliki sifat-sifat utama yaitu memiliki daya hasil yang tinggi, biji yang berkualitas tinggi, dan resisten terhadap serangan hama dan penyakit. Ketersedian bahan tanam atau bibit kakao unggul merupakan salah satu upaya dalam meningkatkan produksi dan mutu kakao Indonesia (Rubiyo, 2009). Namun masyarakat petani kakao Desa Patampanua Kecamatan Marioriawa Kabupaten Soppeng pada umumnya masih banyak yang belum mengetahui bagaimana cara memperoleh bibit kakao yang unggul dan pemeliharaan bibit kakao sampai siap tanam.

Oleh karena itu dengan diadakannya kegiatan PKM- Pengabdian Kepada Masyarakat Pemberdayaan Anak Putus Sekolah Melalui Kakao SANGGUP (Sambung Pucuk) itu dapat mengatasi masalah yang dihadapi masyarakat Desa

\section{Tujuan Kegiatan}

\section{Bahan dan Metode}

Adapun tahapan dan metode pelaksanaan yang di lakukan pada kegiatan ini adalah sebagai berikut :

\section{Tahap Awal}

Pada Tahap awal tim melakukan sosialisai kepada masyarakat terhadap program yang akan dilaksanakan serta komunikasi dengan mitra dan tokoh masyarakat setempat. Selain itu tim juga mempersiapkan segala jenis kebutuhan untuk pelaksanaan penyuluhan seperti materi, tempat kegiatan, serta bahan-bahan yang di butuhkan pada saat penyuluhan dan pelatihan.
Kegiatan ini bertujuan untuk memberdayakan anak putus sekolah di Desa Patampanua, Kecamatan Marioriwawo, Kabupaten Soppeng, dalam melaksanakan pembibitan kakao metode sambung pucuk (okulasi) persilangan dengan kakao unggul.

Patampanua. Pemberdayaan kakao SANGGUP (Sambung Pucuk) adalah pembibitan kakao dengan metode sambung pucuk, yaitu bibit kakao disilangkan dengan kakao yang unggul dan tahan terhadap penyakit. Agar bibit kakao yang diperoleh nantinya adalah bibit kakao yang unggul dan tahan penyakit.

Program tersebut ditujukan kepada generasi muda yang tidak produktif, dengan memberikan pelatihan kepada anak yang putus sekolah untuk menghasilkan bibit kakao yang unggul. Bibit kakao tersebut dapat dijual kepada petani kakao yang ada di Desa Patampanua dapat menjadi sumber penghasilan anak yang putus sekolah dan mengatasi masalah yang dihadapi petani kakao di Desa Patampanua karena sudah dapat menggunakan bibit yang unggul dan produktif.

\section{Tahap Pelaksanaan}

Metode pelaksanaan program ini adalah sebagai berikut :

1. Analisis Pengetahuan Awal Peserta

Metode analisis yang di gunakan adalah dengan cara memberikan quisener yang telah di siapkan. Hal ini dilakukan dengan tujuan untuk mengetahui sejauh mana pengetahuan awal perserta.

2. Metode Ceramah

Memberikan materi mengenai sambung pucuk yang disusun dalam bentuk modul. Materi yang di bawakan yaitu mengenai penjaaran ke unggulan bercocok tanam kakao, 
penyakit yang menyerang tananam

kakao dan cara mengatasi apabila tanaman kakao terserang penyakit.

Sehingga masyarakat dan anak yang putus sekolah bersemangat kembali untuk memajukan daerahnya dengan bercocok tanam kakao. Selain itu juga memberikan pemahaman tentang bagaimana cara merawat bibit kakao yang baik.

3. Metode Diskusi

Metode diskusi ditempuh dengan memberikan kesempatan pada masyarakat untuk melakukan dialog, berbagi pengalaman mengenai masalah yang dihadapi dalam bertani.

4. Metode Pelatihan Anak Putus Sekolah dengan Kakao SANGGUP

Mensimulasikan praktek pengerjaan sambung pucuk, yaitu menyiapakan bibit kakao yang siap untuk di silangkan dan entries kakao yang unggul untuk disilangkan. Pertama yaitu memberikan contoh praktek pelaksanaan sambung pucuk pada bibit kakao dan setelah itu memberikan kesempatan pada masyarakat untuk mempraktekkan ulang dan tetap dalam pengawasan. Apabilah masyarakat masih kurang mengerti proses pengerjaannya maka diberikan contoh lagi sampai benarbenar mahir.

5. Anilisis Pengetahuan Akhir Peserta

Metode analisis yang digunakan adalah dengan cara memberikan quisener yang sama pada tahap analisis pengetahuan awal peserta. Hal ini dilakukan dengan tujuan untuk mengetahui keberhasilan pelaksanaan penyuluhan.

\section{Tahap Akhir}

Tahap akhir yang dilaksanakan adalah menganalisis pengetahuan dan keterampilan peserta penyuluhan serta meninjau keberlanjutan program dan menyusun laporan kemajuan.

\section{Hasil dan Pembahasan}

\begin{tabular}{rcrr} 
Hasil & yang di capai & dalam \\
pelaksanaan & program ini & adalah \\
peningkatan & \multicolumn{2}{c}{ keterampilan } & dan
\end{tabular}
pengetahuan terhadap peserta penyuluhan dan pelatihan kakao sambung pucuk.

\section{Pengetahuan}

Hasil yang dicapai pada konteks pengetahuan yaitu dari ketidak tahuan menadi tahu. Hal ini dibuktikan dengan pre tes dan post tes yang berikan, pada saat pre tes nilai rata-rata peserta yang dicapai hanya 1.5 . Akan tetapi setelah melakukan penyuluhan dengan meberikan materi dan pelatiahan sambung pucuk pada bibit kakao dan nilai rata-rata yang di capai peserta pada post tes menjadi 8.65. Melihat dari hasil yang dicapai kami mengaggap bahwa penyuluhan ini berhasil.

\section{Keterampilan}

Penyuluhan ini juga memberikan peningkatan keterampilan pada peserta penyuluhan, yaitu keterampilan dalam melakukan sambung pucuk pada bibit kakao. Dalam melakukan sambung pucuk pada bibit kakao, keterampilan sangat dibutuhkan agar sambung pucuk yang dilakukan dapat berhasil. Apabilah kita tidak terampil atau tidak mahir dalam melakukannya kemungkinan berhasilnya sambung pucuk sangat rendah. Salah satu keterampilan yang sangat penting yaitu pada penyayatan entris kakao, apabilah kita tidak terampil dalam melakukannya 
maka sambungan yang dilakukan tidak berhasil atau mati.

Dari hasil pelatihan yang diberikan keterapilan peserta cukup bagus hal ini dapat dilihat dari jumlah bibit yang berhasil tumbuh. Pada pelatihan yang pertama dari 100 bibit yang sambung pucuk hanya 30 yang berhasil tumbuh, akan tetapi pada saat pelatiahan yang kedua menuai hasil yang memuaskan yaitu dari 100 bibit yang di sambung 70 bibit berhasil tumbuh.

\section{Simpulan}

Sambung pucuk merupakan proses perbanyakan tanaman secara vegetative dengan tujuan untuk memperoleh varietas tanaman yang lebih baik karena tunas hasil sabung pucukan tumbuh dan berkembang dengan mengambil sifat-sifat dominan dari kedua tumbuhan. Oleh karena itu sambung pucuk pada kakao merupakan salah satu alternatif untuk menangani masalah kakao dari berbagai penyakit. Melalui pelatiahan yang diberikan bertujuan untuk meningkatkan pengetahuan dan keterampilan dalam melakukan sambung pucuk pada bibit kakao agar dapat menggunakan bibit unggul pada pekebunan kakao di masyarakat setempat.

\section{Daftar Pustaka}

Badan Pusat Statistik Kabupaten Soppeng , 2017. Statistik Indonesia Tahun 2010. Kabupaten Soppeng : Badan Pusat Statistik

Rubiyo. 2013.Ketahanan Tanaman Kakao Terhadap Penyakit busuk Buah (Phytophthora palmivora Bult.). Balai Penelitian Tanaman Industridan Penyegar. 